\title{
Public Awareness and Identification of Counterfeit Drugs in Tanzania: A View on Antimalarial Drugs
}

\author{
Linus Mhando, ${ }^{1}$ Mary B. Jande, ${ }^{2}$ Anthony Liwa, ${ }^{3}$ Stanley Mwita, ${ }^{2}$ and Karol J. Marwa ${ }^{3}$ \\ ${ }^{1}$ Institute of Allied Sciences, Catholic University of Health and Allied Sciences, Mwanza, Tanzania \\ ${ }^{2}$ School of Pharmacy, Catholic University of Health and Allied Sciences, Mwanza, Tanzania \\ ${ }^{3}$ Department of Pharmacology, Catholic University of Health and Allied Sciences, Mwanza, Tanzania
}

Correspondence should be addressed to Karol J. Marwa; carol_maro@yahoo.com

Received 20 February 2016; Revised 9 May 2016; Accepted 17 May 2016

Academic Editor: Ronald J. Prineas

Copyright (C) 2016 Linus Mhando et al. This is an open access article distributed under the Creative Commons Attribution License, which permits unrestricted use, distribution, and reproduction in any medium, provided the original work is properly cited.

\begin{abstract}
Background. The illicit trade in counterfeit antimalarial drugs is a major setback to the fight against malaria. Information on public awareness and ability to identify counterfeit drugs is scanty. Aim. Therefore, the present study aimed at assessing public awareness and the ability to identify counterfeit antimalarial drugs based on simple observations such as appearance of the drugs, packaging, labelling, and leaflets. Methodology. A cross-sectional study was conducted using interviewer administered structured questionnaire and a checklist. Respondents were required to spot the difference between genuine and counterfeit antimalarial drugs given to them. Data was analysed using SPSS version 20. Results. The majority of respondents, 163 (55.6\%), were able to distinguish between genuine and counterfeit antimalarial drugs. Respondents with knowledge on health effects of counterfeit drugs were more likely to identify genuine and counterfeit drugs than their counterparts $(P=0.003$; OR $=2.95 ; 95 \% \mathrm{CI}: 1.47-5.65)$. The majority of respondents, 190 $(64.8 \%)$, perceived the presence of counterfeit drugs to be a big problem to the community. Conclusions. A substantial proportion of respondents were able to distinguish between genuine and counterfeit antimalarial drugs. Public empowerment in identifying counterfeit drugs by simple observations is a major step towards discouraging the market of counterfeit drugs.
\end{abstract}

\section{Introduction}

There is a wide variation on how various nations define counterfeit drugs [1]. The WHO defines counterfeit pharmaceutical product as a product which is deliberately and fraudulently mislabelled with respect to identity and/or source [2]. Counterfeiting can apply to both branded and generic products and counterfeit drugs may include products with the correct ingredients but fake packaging, incorrect ingredients, no active ingredients, or insufficient active ingredients and toxins $[2,3]$.

Counterfeiting is regarded as one of the oldest crimes in history [4]. The history of counterfeit/fake drugs goes back to several millennia ago with references to a supply of fake antimalarials: cinchona in the early 1600s and quinine in the 1800s [3]. Currently, it is estimated that $10-15 \%$ of the global drugs supplied are counterfeit $[3,5]$. The prevalence is higher in developing countries in Africa and in parts of Asia and Latin America where up to $30-60 \%$ of drugs on the market are counterfeit $[3,5-9]$. India is a major supplier of poor quality drugs whereby $35-75 \%$ of fake/counterfeit drugs globally originate from India $[10,11]$.

The most affected people with counterfeit drugs are the poor living in developing countries $[8,12-15]$ where selfmedication is common and in a few of these countries in Africa drugs are sold through the informal economy in openair markets together with vegetables and fruits or by hawkers alongside newspaper vendors [16, 17]. Counterfeit drugs are a major cause of therapeutic failure, serious adverse events, deaths, economic burden, drug resistance, and loss of public confidence in drugs and health services [7, 8, 12, 14, 18-23].

The economic effects resulting from counterfeiting drugs are of great significance in developing countries in terms of lost sales revenues, lost tax revenues, lost jobs, costs incurred in combating these counterfeit drugs, and wasted money by poor people to purchase these drugs plus frequency hospitalization due to therapeutic failure [24-26]. 
Drug counterfeiting is nowadays regarded as murder or terrorism and the greatest evil against human health and economy [27-29]. Statistics support this as it is estimated that, out of one million deaths reported due to malaria, 200,000450,000 are contributed by the use of counterfeit or fake drugs $[24,29]$. The World Health Organization estimates that counterfeit drugs potentially make up more than $50 \%$ of the global drug market with a significant proportion of these fake products coming from developing countries [8].

Antimalarials like other anti-infectives are among the most counterfeited drugs globally [3, 14, 28, 30] and there is a diversity of counterfeit packaging types [12]. Studies done in South East Asia indicate that a high proportion of antimalarials in the market are counterfeit where $38-53 \%$ of artesunate tablets do not contain active ingredient $[20,31]$ and the problem is increasing significantly globally [20,23]. The illicit trade in counterfeit antimalarial drugs is a great threat to lives of patients and the fight against malaria [31-33] due to the fact that such patients treated with counterfeit drugs are at a high risk of developing severe malaria and occurrence of death [23].

Antimalarials are among the most targeted drugs in counterfeit black trade in Africa. The continent accounts for approximately $90 \%$ of the 300 million global cases of malaria $[34,35]$. Consequently, antimalarials are the most used drugs in African tropical countries like Tanzania which have a high burden of malaria and other infections/infestations [36, 37].

In Uganda, which is a neighboring country to Tanzania, $37 \%$ of artemisinin based combination therapies (ACTs) sold in private drug shops are fake/counterfeit [38]. Tanzania, being a developing country, is not an exception as far as counterfeit drugs are concerned. Counterfeit antimalarial drugs have been identified in Tanzania, a good example being sulphadoxine-pyrimethamine (Metakelfin, $500 \mathrm{mg} / 25 \mathrm{mg}$ ) and dihydroartemisinin (60 mg per tablet, Cotecxin in 200) $[23,39,40]$. These products use identical batch numbers, identical expiry dates, and identical packaging with the purpose of ensuring that they look like the genuine product $[23,39]$.

The rapid increase in black market in counterfeit drugs in Africa and other parts of the world is attributed to the widespread use of the Internet to market counterfeit drugs, advanced computer technologies which allow forging labels, weakness in regulatory systems, neglect of good manufacturing practice, lack of awareness among health workers and the public, corruption, and a large profit potential from the black counterfeit market $[28,39,41-43]$. The Internet has a significant impact especially in developed countries as it is estimated that $50 \%$ of drugs purchased through the Internet are fake [44].

Unfortunately, the illegal trade in counterfeits has now extended to herbal drugs which are mostly used in developing countries [37]. Counterfeiting is also conceded as a major threat to pharmaceutical firms and these firms are now employing various strategies to combat counterfeiting including partnership with governments and health advocates [25, 45].

The WHO and studies recommend the need for public awareness on the growing trade in counterfeit drugs and the public health risks associated with it $[16,21]$. However, information on public awareness on counterfeit drugs and the ability to identify or suspect counterfeited drugs is scanty.

The WHO established guidelines for combating counterfeit drugs in 1999 [46] and launched the International Medical Products Anti-Counterfeiting Taskforce (IMPACT) which included national drug regulatory authorities and law enforcement agencies in 2006 aiming at putting an end to the illicit trade in fake/counterfeit drugs [16]. Many strategies for eliminating counterfeit drugs in the market have therefore been established. These include establishment of strict laws, enforcement/legal actions on illicit traders, application of fast and reliable detection/analysis of the suspect products to distinguish genuine from counterfeit drugs, education and information to the public who are the consumers, improvement on the management of supply chain, and improvement on controls of secondary markets [41, 47, 48].

Despite much efforts put to implement the proposed strategies, the trade in counterfeit drugs has increased significantly. Only few countries have succeeded in this war against illicit traders in counterfeit drugs, Nigeria being an example where a decrease has been recorded significantly from $41 \%$ (2002) to $10 \%$ (2011) and the country is seeking to eradicate counterfeits in the market $[15,49,50]$. There is a strong need of understanding the mechanisms and structure of the illicit market of counterfeit drugs, consumer's behavior, and maneuvers used by counterfeiters of drugs.

A counterfeit drug may look like the genuine version of the drug. Unfortunately, the only way to confirm whether it is counterfeit is by performing a chemical analysis in a laboratory. However, signs such as different doses of medicine inside the packs from those stated on the outside, the pack containing capsules when the box states tablets, expiry dates and batch numbers on the box not matching those of the drugs inside, and patient's information leaflets being in the wrong language or out of date may indicate whether a drug/product is counterfeited.

Awareness of respondents on these signs is important towards suspicion of counterfeit drugs and avoidance of buying such drugs consequently reducing the market and profit of these illicit drugs.

Therefore, the present study was carried out to assess public awareness and the ability to identify antimalarial drugs which are commonly used in Tanzania.

\section{Methods}

2.1. Study Population. This cross-sectional study was conducted between January and November 2014 in Mwanza city, Tanzania. Mwanza is a malaria endemic area.

2.1.1. Sampling Procedure. Multistage sampling technique was used to select wards and streets. Then, random sampling was employed to select respondents from the selected streets.

2.1.2. Questionnaire and Data Collection. The questionnaire was developed in English and translated into the 


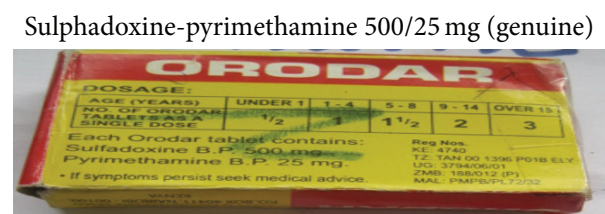

Sulphadoxine-pyrimethamine 500/25 mg (counterfeit)

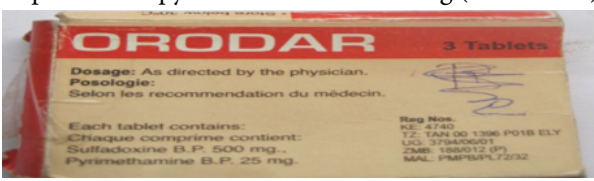

FIGURE 1

local language (Swahili) and then administered through face-to-face interviews. Pretesting of the questionnaire was done at Mkuyuni Ward in Mwanza to assess practicability and respondent's understanding of the questionnaire. Each respondent was given four antimalarial drug samples to distinguish between genuine and counterfeit drugs based on observations while giving specific reason(s)/justifications for his/her choice. Respondents were not informed of the issues to look for before in order to avoid bias as the study aimed at respondent's experience. A checklist was then used to evaluate respondent's ability to distinguish between genuine and counterfeit drugs. The questionnaire captured the information on the sociodemographic characteristics, public perception on counterfeit drugs, source(s) of information on counterfeit drugs, and recommendations on measures to be taken to control the illicit trade in counterfeit drugs.

The four antimalarial drugs samples used were sulphadoxine-pyrimethamine 500/25 mg (Orodar ${ }^{\circledR}$ ) made by Elys Chemical Industries Ltd. and its counterfeit and sulfametopyrazine-pyrimethamine $\left(\right.$ Laefin $^{\circledR}$ ) and its counterfeit (Figures 1 and 2). These drug samples were obtained from the Tanzania Food and Drugs Authority (TFDA), Mwanza branch. The above SP drugs have now been replaced by artemisinin based combination therapies (ACTs) as first lines of treatment of uncomplicated malaria and are only reserved for intermittent preventive treatment (IPT) for malaria during pregnancy. However, these drugs were picked because most patients still use them widely for treatment of uncomplicated malaria and they are the most reported to be counterfeited among antimalarial drugs in Tanzania.

2.2. Data Processing and Analysis. Data was analysed using the Statistical Package for Social Sciences (SPSS) version 20. Chi-square and Fischer's exact tests were performed for determining association between independent variables and public ability to distinguish counterfeit antimalarial drugs. Strength of association of public ability to distinguish counterfeit drugs with independent variables was analysed by using bivariate logistic regression analysis. Odds ratios (OR) and 95\% confidence intervals (95\% CI) were reported as a measure of effect. A $P$ value of $\leq 0.05$ was considered statistically significant.

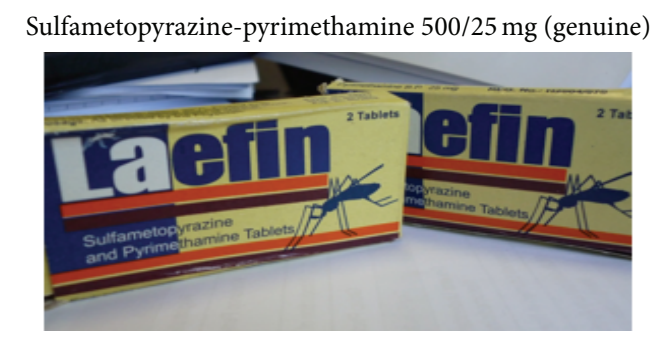

Sulfametopyrazine-pyrimethamine 500/25 mg (counterfeit)

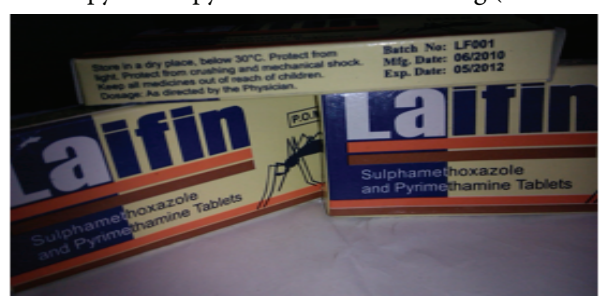

Figure 2

2.3. Ethical Consideration. Ethical and study approval was granted by the joint Catholic University of Health and Allied Sciences/Bugando Medical Centre institutional review board. Further permission was sought from the regional medical officer, ward executive officers, and village executive leaders. All respondents signed written informed consent and were guaranteed privacy and confidentiality.

\section{Results}

3.1. Sociodemographic Characteristics of the Interviewed Respondents. In this study, a total of 293 respondents were enrolled; the mean age was 28 years $(S D=6.12)$. About 187 $(63.8 \%)$ of the respondents were males and 106 (36.2\%) were females. A total of $128(43.7 \%)$ respondents had primary education and $3(1 \%)$ had never been to school. The majority of respondents were married 206 (70.3\%), whereas $87(29.7 \%)$ were single. Among the respondents, 184 (62.8\%) were unemployed (Table 1).

3.2. Factors Enabling Respondents to Distinguish Counterfeit and Genuine Drugs. Among the interviewed respondents, $163(55.6 \%)$ were able to distinguish between a genuine and a counterfeit drug while $130(44.4 \%)$ failed. The majority of the respondents with health profession (84\%) were able to distinguish a genuine drug from a counterfeit antimalarial drug ( $P$ value 0.003 ) (Table 2$)$.

3.3. Information on Counterfeit Drugs. The majority of respondents, $202(68.9 \%)$, mentioned media to be a source of information on counterfeit drugs and only $12(4.1 \%)$ mentioned health facilities as a source of information.

\subsection{Factors Affecting Ability to Distinguish between Genuine} and Counterfeit Antimalarial Drugs. Table 4 shows the association of factors enabling distinguishing between genuine and counterfeit drugs. There was a significant association between knowledge on health effects of counterfeit drugs 
TABLE 1: Sociodemographic characteristics of the respondents.

\begin{tabular}{lcc}
\hline Characteristics & Frequency & Percent \\
\hline Age group & 76 & \\
$18-28$ & 137 & 25.90 \\
$29-39$ & 60 & 46.80 \\
$40-50$ & 13 & 20.50 \\
$51-61$ & 7 & 4.40 \\
Above 62 & & 2.40 \\
Sex & 187 & \\
Male & 106 & 63.80 \\
Female & & 36.20 \\
Respondents education & 128 & \\
Primary & 72 & 43.70 \\
Secondary & 90 & 24.60 \\
College or above & 3 & 30.70 \\
$\quad$ None & & 1.00 \\
Marital status & 206 & \\
Married & 87 & 70.30 \\
Single & & 29.70 \\
Respondent occupation & 25 & \\
Health workers & 84.50 \\
Non-health workers & & \\
Unemployed & & \\
\hline
\end{tabular}

and knowledge of distinguishing features with distinction of genuine and counterfeit drugs ( $P$ value: 0.015 and 0.005$)$, respectively.

Respondents who had knowledge on health effects of counterfeit drugs were nearly 3 times more likely to distinguish genuine and counterfeit drugs than their counterparts $(\mathrm{OR}=2.95 ; 95 \% \mathrm{CI}=1.47-5.65)$. Those with health profession were 2.1 times more likely to distinguish between genuine and counterfeit drugs $(\mathrm{OR}=2.16 ; 95 \% \mathrm{CI}=1.248-3.733)$ than non-health workers (Table 5).

3.5. Distinguishing Features between Genuine and Counterfeit Drugs. Respondents with knowledge on packaging material as a distinguishing feature were 5.7 times more likely to distinguish the drugs compared to those with knowledge on expiry date; similarly, those with knowledge on label/legitimacy were 7.4 times more likely to distinguish the drugs compared to those with knowledge on expiry date, both being of highly statistical significance with $P<0.0001$ (Table 6).

3.6. Magnitude on the Concerns on Counterfeit Drugs. In this study, most of the interviewed respondents, 190 (64.8\%), reported the magnitude of counterfeit drugs to be a big problem, 99 (33.8) did not know the extent of counterfeit drugs, and a few, 4 (1.4\%), reported that counterfeit drugs do not exist.
3.7. Public Advice on Measures to Reduce Counterfeit Drugs Proliferation. Most respondents, 134 (45.7\%), reported that counterfeit drugs will be successfully reduced through sensitizing people's awareness against counterfeit drugs. Adherence to ethics, 87 (29.7\%), strictness of entry points (borders), $41(14 \%)$, and the necessity of authorizing pharmacy dealers, $17(5.8 \%)$, were also suggested. Only a few respondents, 14 (4.8\%), emphasized the need for TFDA to adhere to/carry on surveillance several times.

\section{Discussion}

The WHO and studies recommend the need for public awareness on the growing trade in counterfeit drugs and the public health risks associated with it $[16,21]$. This study has explored public awareness and identification of counterfeit antimalarial drugs. Antimalarial drugs were chosen because they are the most counterfeited and are commonly used in developing countries such as Tanzania where malaria is endemic, the market of counterfeit antimalarial drugs is high, and self-medication is common [36, 37]. Therefore, it is expected that respondents frequently use antimalarial drugs and are mostly likely to recognize these drugs based on the past experience and frequency of use. Respondent's awareness and ability to identify counterfeit drugs qualitatively based on packaging, labelling, and appearance/colour are an important step towards creating suspicion and discouraging the illicit trade in counterfeit drugs for malaria and other conditions.

A substantial number of respondents were able to distinguish between genuine and counterfeit antimalarial drugs. This finding is encouraging with regard to the fight against illicit trade in counterfeit antimalarial drugs in developing countries where 200,000-450,000 deaths out of one million reported due to malaria result from the use of counterfeit or fake drugs $[24,29]$. Recognition of counterfeit/fake drugs by the public is expected to decrease the purchase of such drugs in the market.

With regard to the correlation between knowledge on distinguishing features and ability to identify counterfeit drugs, the majority of those who had knowledge on labelling as a way of identifying a counterfeit drug were able to identify counterfeit antimalarial drugs (Table 4). A similar observation is recorded with those who knew packaging material is used in identifying counterfeit drugs (Table 4). A significant proportion of those with knowledge on expiry date and country of origin as distinguishing features used were also able to identify counterfeit drugs compared to those aware of brand name.

The majority of the respondents (84\%) with health profession background were able to distinguish genuine against counterfeit antimalarial drugs compared to their counterparts who did not have health profession background (Tables 2 and 4). This finding is encouraging since health care workers are supposed to be in a front line in the fight against counterfeit drugs as per WHO recommendation [2]. However, when logistic regression was performed, health profession background was not a strong predictor for identification of counterfeit antimalarial drugs (Table 5). 
TABLE 2: Sociodemographic characteristics of the respondents and the ability to distinguish between genuine and counterfeit drugs.

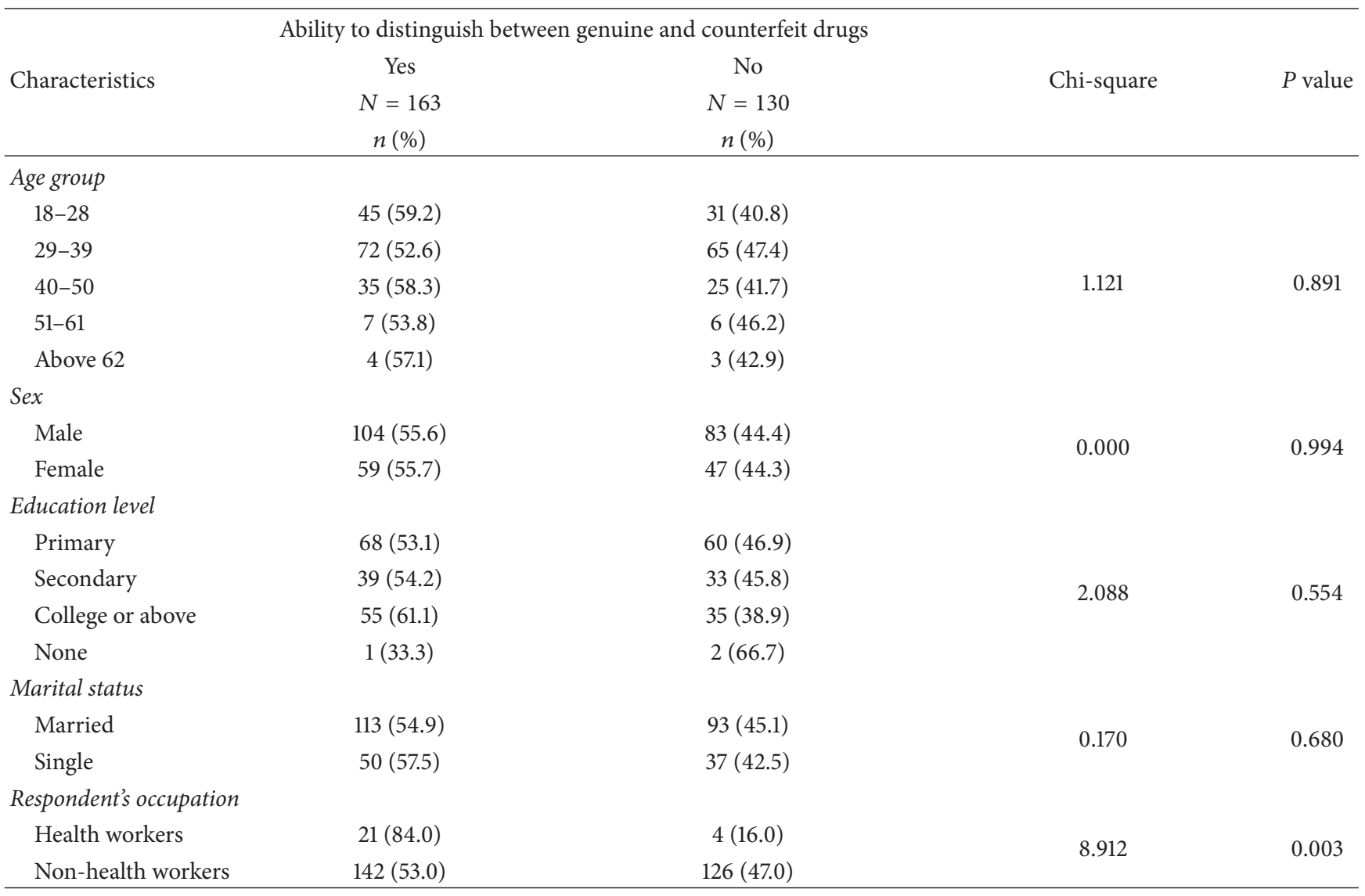

TABLE 3: Distribution of respondents according to source of information on counterfeit drugs.

\begin{tabular}{lcc}
\hline Source of information on counterfeit drugs & Frequency & Percent \\
\hline Media & 202 & 68.90 \\
Relatives and friends & 49 & 16.70 \\
Schools & 16 & 5.50 \\
Advertising materials & 14 & 4.80 \\
Health facilities & 12 & 4.10 \\
\hline Total & 293 & 100.00 \\
\hline
\end{tabular}

The only strong predictor for identification of counterfeit drugs recorded was knowledge on health effects of counterfeit drugs (Table 5).

Conversely, age, sex, education level, and marital status were not borne out to be determinants for identification of counterfeit drugs (Table 2).

The media were established as the main source of information on counterfeit drugs to the community (Table 3). Respondents perceived the presence of counterfeit drugs in the community to be a big problem. Respondent's views on how to reduce the magnitude of counterfeit drugs include sensitizing people awareness against counterfeit drugs, adherence to ethics, strictness of entry points, and the necessity of authorized pharmacy dealers and adherence to surveillance several times by the FDA.

Community involvement is a neglected issue in the fight against the illicit trade in counterfeit drugs. The present study establishes a need for further empowering the community to enable consumers to identify/suspect counterfeit or fake drugs for common diseases/conditions such as malaria based on physical observation, thus acting as a primary source of information to FDA which will further confirm the suspicion of counterfeit drugs by employing laboratory techniques.

\section{Conclusion}

A substantial proportion of respondents were able to distinguish between genuine and counterfeit drugs. The main source of information on counterfeit drugs was the media. There is a need of empowering the public in identifying counterfeit drugs for common diseases like malaria by simple observations as a major step towards discouraging the market of counterfeit drugs and part of postmarketing surveillance.

\section{Abbreviations}

TFDA: Tanzania Food and Drug Authority

FDA: Food and Drug Authority

WHO: World Health Organization. 
TABLE 4: Association of factors affecting ability to distinguish between genuine and counterfeit drugs.

\begin{tabular}{|c|c|c|c|c|}
\hline \multirow[b]{2}{*}{ Factors } & \multicolumn{3}{|c|}{ Ability to distinguish between genuine and counterfeit drugs } & \multirow[b]{2}{*}{$P$ value } \\
\hline & $\begin{array}{c}\text { Yes } \\
N=163 \\
n(\%)\end{array}$ & $\begin{array}{c}\text { No } \\
N=130 \\
n(\%)\end{array}$ & Chi-square & \\
\hline \multicolumn{5}{|c|}{ Knowledge on health effects of counterfeit drugs } \\
\hline Yes & $138(58.2)$ & $99(41.8)$ & \multirow{2}{*}{3.387} & \multirow{2}{*}{0.015} \\
\hline No & $25(44.6)$ & $31(55.4)$ & & \\
\hline \multicolumn{5}{|c|}{ Knowledge on economic effects of counterfeit drugs } \\
\hline Yes & $30(47.6)$ & $33(52.4)$ & \multirow{2}{*}{2.087} & \multirow{2}{*}{0.149} \\
\hline No & $133(57.8)$ & $97(42.2)$ & & \\
\hline \multicolumn{5}{|c|}{ Knowledge of distinguishing features } \\
\hline Label/legitimacy & $68(54.4)$ & $57(45.6)$ & \multirow{6}{*}{8.736} & \multirow{6}{*}{0.005} \\
\hline Packaging material & $50(55.6)$ & $40(44.4)$ & & \\
\hline Expiry date & $23(57.5)$ & $17(42.5)$ & & \\
\hline Country of origin & $7(63.6)$ & $4(36.4)$ & & \\
\hline Brand name & $9(47.4)$ & $10(52.6)$ & & \\
\hline ISO certification & $6(75.0)$ & $2(25.0)$ & & \\
\hline \multicolumn{5}{|c|}{ Source of information on counterfeit drugs } \\
\hline Media & $108(53.5)$ & $94(46.5)$ & \multirow{5}{*}{4.977} & \multirow{5}{*}{0.290} \\
\hline Relatives and friends & $26(53.1)$ & $23(46.9)$ & & \\
\hline Schools & $10(62.5)$ & $6(37.5)$ & & \\
\hline Advertising materials & $9(64.3)$ & $5(35.7)$ & & \\
\hline Health facilities & $10(83.3)$ & $2(16.7)$ & & \\
\hline
\end{tabular}

TABLE 5: Logistic regression on factors associated with identification of genuine and counterfeit drugs.

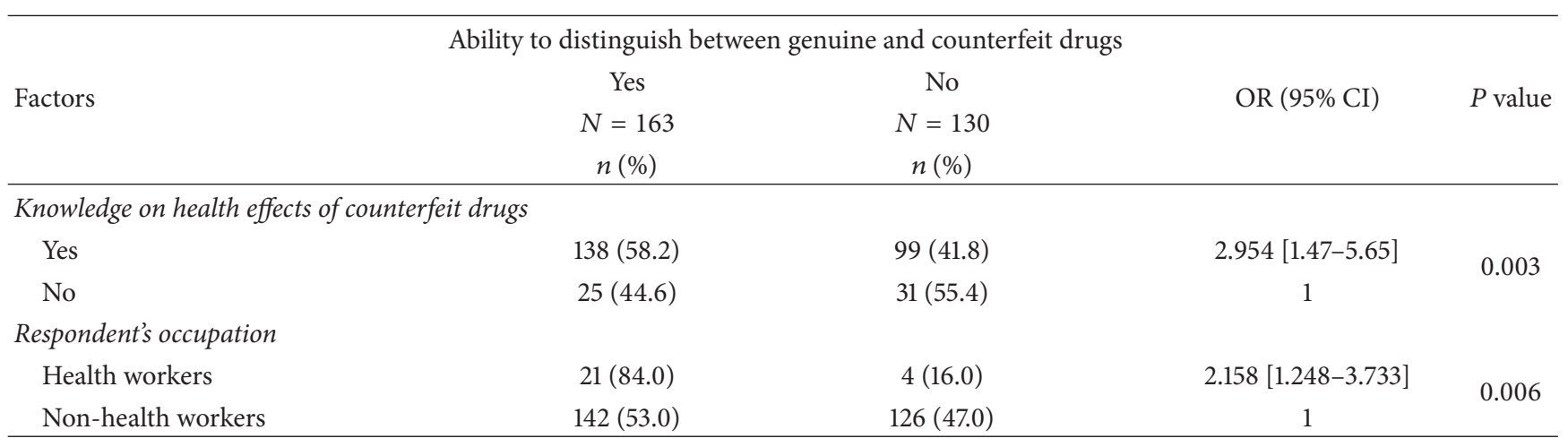

TABLE 6: Association of distinguishing features and identification of genuine and counterfeit drugs.

\begin{tabular}{lcccc}
\hline Distinguishing features & $N$ & $(\%)$ & OR & $P$ value $(95 \%$ CI $)$ \\
\hline Expiry date & 40 & 13.7 & 1 & \\
Packaging material & 101 & 34.5 & 5.7 & $P<0.0001(3.7-12.7)$ \\
Label/legitimacy & 152 & 51.9 & 7.4 & $P<0.0001(4.1-15.6)$ \\
\hline
\end{tabular}

\section{Disclosure}

The main author received a financial support from the Catholic University of Health and Allied Sciences as part of his studies.

\section{Competing Interests}

The authors declare that they have no competing interests. The financial support offered by the university to the main author as part of his studies does not lead to any conflict of interests.

\section{Authors' Contributions}

Karol J. Marwa participated in proposal development, sample collection, data analysis, and paper drafting and submitting. Linus Mhando participated in proposal development, sample collection, data analysis, and paper drafting. Mary B. Jande, 
Stanley Mwita, and Anthony Liwa participated in proposal development, paper revising, and approval for publication.

\section{Acknowledgments}

The authors sincerely thank the respondents who volunteered to take part in the study, the Catholic University of Health and Allied Sciences, and the regional medical officer for granting them a permission to carry out the study and TFDA at Lake Zone offices in Mwanza city.

\section{References}

[1] C. Clift, Combating Counterfeit, Falsified and Substandard Medicines: Defining the Way Forward? Chatham House, London, UK, 2010.

[2] WHO, Counterfeit and Substandard Drugs in Myanmar and Vietnam, World Health Organization, Geneva, Switzerland, 1999.

[3] P. N. Newton, M. D. Green, and F. M. Fernández, "Impact of poor-quality medicines in the 'developing' world," Trends in Pharmacological Sciences, vol. 31, no. 3, pp. 99-101, 2010.

[4] N. Hamelin, S. Nwankwo, and R. El Hadouchi, "'Faking brands': consumer responses to counterfeiting," Journal of Consumer Behaviour, vol. 12, no. 3, pp. 159-170, 2013.

[5] R. Cockburn, P. N. Newton, E. K. Agyarko, D. Akunyili, and N. J. White, "The global threat of counterfeit drugs: why industry and governments must communicate the dangers," PLoS Medicine, vol. 2, no. 4, article 302, 2005.

[6] T. Almuzaini, I. Choonara, and H. Sammons, "Substandard and counterfeit medicines: a systematic review of the literature," BMJ Open, vol. 3, no. 8, Article ID e002923, 2013.

[7] P. Schlagenhauf and E. Petersen, "Antimalaria drug resistance: the mono-combi-counterfeit triangle," Expert Review of AntiInfective Therapy, vol. 7, no. 9, pp. 1039-1042, 2009.

[8] B. D. Glass, "Counterfeit drugs and medical devices in developing countries," Research and Reports in Tropical Medicine, vol. 2014, no. 5, pp. 11-22, 2014.

[9] R. Bate and K. Boateng, "Bad medicine in the market," World Hospitals and Health Services, vol. 43, no. 3, pp. 17-21, 2007.

[10] D. K. Mali, S. S. Mitkare, R. S. Moon, and R. Kshirsagar, "Anticounterfeit packaging in pharma industry: review," International Journal of Pharmacy and Pharmaceutical Sciences, vol. 3, no. 3, article 46, 2011.

[11] D. N. Akunyili, "Counterfeit drugs and pharmacovigilance," in Proceedings of the 10th Pharmacovigilance Training Course held at Uppsala Monitoring Centre, Uppsala, Sweden, May 2005.

[12] P. N. Newton, M. D. Green, F. M. Fernández, N. P. Day, and N. J. White, "Counterfeit anti-infective drugs," Lancet Infectious Diseases, vol. 6, no. 9, pp. 602-613, 2006.

[13] A. I. Wertheimer, N. M. Chaney, and T. Santella, "Counterfeit pharmaceuticals: current status and future projections," Journal of the American Pharmacists Association, vol. 43, no. 6, pp. 710718, 2003.

[14] H. Tadeg and Y. Berhane, "Substandard and counterfeit antimicrobials: recent trends and implications to key public health interventions in developing countries," East African Journal of Public Health, vol. 9, no. 2, pp. 85-89, 2012.

[15] A. Khan and N. Ghilzai, "Counterfeit and substandard quality of drugs: the need for an effective and stringent regulatory control in India and other developing countries," Indian Journal of Pharmacology, vol. 39, no. 4, pp. 206-207, 2007.

[16] W. Burns, "WHO launches taskforce to fight counterfeit drugs," Bulletin of the World Health Organization, vol. 84, no. 9, pp. 689690, 2006.

[17] O. Chinwendu, The Fight against Fake Drugs by NAFDAC in Nigeria, Royal Tropical Institute (KIT), Amsterdam, The Netherlands, 2008.

[18] C. S. Gautam, A. Utreja, and G. L. Singal, "Spurious and counterfeit drugs: a growing industry in the developing world," Postgraduate Medical Journal, vol. 85, no. 1003, pp. 251-256, 2009.

[19] A. I. Wertheimer and J. Norris, "Safeguarding against substandard/counterfeit drugs: mitigating a macroeconomic pandemic," Research in Social and Administrative Pharmacy, vol. 5, no. 1, pp. 4-16, 2009.

[20] A. M. Dondorp, P. N. Newton, M. Mayxay et al., "Fake antimalarials in Southeast Asia are a major impediment to malaria control: multinational cross-sectional survey on the prevalence of fake antimalarials," Tropical Medicine and International Health, vol. 9, no. 12, pp. 1241-1246, 2004.

[21] S. E. Nsimba, "Problems associated with substandard and counterfeit drugs in developing countries: a review article on global implications of counterfeit drugs in the era of antiretroviral (ARVs) drugs in a free market economy," East African Journal of Public Health, vol. 5, no. 3, pp. 205-210, 2009.

[22] T. Kelesidis, I. Kelesidis, P. I. Rafailidis, and M. E. Falagas, "Counterfeit or substandard antimicrobial drugs: a review of the scientific evidence," Journal of Antimicrobial Chemotherapy, vol. 60, no. 2, pp. 214-236, 2007.

[23] M. Cordina, Counterfeit medicines.

[24] J. Wilson and R. Fenoff, "The health and economic effects of counterfeit pharmaceuticals in Africa," globalEDGE Business Review, vol. 5, no. 6, pp. 1-2, 2011.

[25] B. Waka, Response Strategies of Haco Industries Kenya Limited to the Challenges of Counterfeit Products in East Africa, University of Nairobi, 2007.

[26] L. Meeking, "Counterfeit economy: the impacts of counterfeit goods on African society: Africa-wide-featured analysis," Africa Conflict Monthly Monitor, pp. 8-12, 2013.

[27] P. Aldhous, "Counterfeit pharmaceuticals: murder by medicine," Nature, vol. 434, no. 7030, pp. 132-136, 2005.

[28] D. Akunyili, "Fake and counterfeit drugs in the health sector: the role of medical doctors," Annals of Ibadan Postgraduate Medicine, vol. 2, no. 2, pp. 19-23, 2004.

[29] K. Karunamoorthi, "The counterfeit anti-malarial is a crime against humanity: a systematic review of the scientific evidence," Malaria Journal, vol. 13, no. 1, article 209, 2014.

[30] P. N. Newton, N. J. White, J. A. Rozendaal, and M. D. Green, "Murder by fake drugs: time for international action," British Medical Journal, vol. 324, no. 7341, pp. 800-801, 2002.

[31] P. Newton, S. Proux, M. Green et al., "Fake artesunate in southeast Asia," The Lancet, vol. 357, no. 9272, pp. 1948-1950, 2001.

[32] G. M. L. Nayyar, J. G. Breman, P. N. Newton, and J. Herrington, "Poor-quality antimalarial drugs in southeast Asia and subSaharan Africa," The Lancet Infectious Diseases, vol. 12, no. 6, pp. 488-496, 2012.

[33] R. Bate, P. Coticelli, R. Tren, and A. Attaran, "Antimalarial drug quality in the most severely malarious parts of Africa-A Six Country Study," PLoS ONE, vol. 3, no. 5, article e2132, 2008. 
[34] R. Kerb, R. Fux, K. Mörike et al., "Pharmacogenetics of antimalarial drugs: effect on metabolism and transport," The Lancet Infectious Diseases, vol. 9, no. 12, pp. 760-774, 2009.

[35] D. Blessborn, S. Römsing, A. Annerberg et al., "Development and validation of an automated solid-phase extraction and liquid chromatographic method for determination of lumefantrine in capillary blood on sampling paper," Journal of Pharmaceutical and Biomedical Analysis, vol. 45, no. 2, pp. 282287, 2007.

[36] O. Onwujekwe, H. Kaur, N. Dike et al., "Quality of anti-malarial drugs provided by public and private healthcare providers in south-east Nigeria," Malaria Journal, vol. 8, no. 1, article 22, 2009.

[37] A. Mullaicharam, "Counterfeit herbal medicine," International Journal of Nutrition, Pharmacology, Neurological Diseases, vol. 1, no. 2, pp. 97-102, 2011.

[38] M. Björkman-Nyqvist, J. Svensson, and D. Yanagizawa, Can Good Products Drive Out Bad?: Evidence from Local Markets for (Fake?) Antimalarial Medicine in Uganda, Centre for Economic Policy Research, 2012.

[39] N. Siva, "Tackling the booming trade in counterfeit drugs," The Lancet, vol. 376, no. 9754, pp. 1725-1726, 2010.

[40] P. N. Newton, R. McGready, F. Fernandez et al., "Manslaughter by fake artesunate in Asia-will Africa be next?" PLoS Medicine, vol. 3, no. 6, article e197, 2006.

[41] D. Bansal, S. Malla, K. Gudala, and P. Tiwari, "Anti-counterfeit technologies: a pharmaceutical industry perspective," Scientia Pharmaceutica, vol. 81, no. 1, pp. 1-13, 2013.

[42] G. J. Buckley and L. O. Gostin, Causes of Falsified and Substandard Drugs, 2013.

[43] R. Koh, E. W. Schuster, I. Chackrabarti, and A. Bellman, "Securing the pharmaceutical supply chain," White Paper, AutoID Labs, Massachusetts Institute of Technology, 2003.

[44] D. Bagozzi, Counterfeit Medicines: Fact Sheet $N^{\circ}$ 275, World Health Organization, 2006.

[45] K. M. Lybecker, "Rx Roulette: combatting counterfeit pharmaceuticals in developing nations," Managerial and Decision Economics, vol. 28, no. 4-5, pp. 509-520, 2007.

[46] WHO, Guidelines for the Development of Measures to Combat Counterfeit Drugs, World Health Organization, Geneva, Switzerland, 1999.

[47] K. Dégardin, Y. Roggo, and P. Margot, "Understanding and fighting the medicine counterfeit market," Journal of Pharmaceutical and Biomedical Analysis, vol. 87, pp. 167-175, 2014.

[48] E. A. Blackstone, J. P. Fuhr Jr., and S. Pociask, "The health and economic effects of counterfeit drugs," American Health and Drug Benefits, vol. 7, no. 4, pp. 216-224, 2014.

[49] D. Akunyili, "Counterfeiting medicines: a serious crime against humanity," in Proceedings of the Director General of the National Agency for Food and Drug Administration and Control (NAFDAC '07), vol. 10, pp. 1-7, April 2007.

[50] A. Chika, S. O. Bello, A. O. Jimoh, and M. T. Umar, "The menace of fake drugs: consequences, causes and possible solutions," Research Journal of Medical Sciences, vol. 5, no. 5, pp. 257-261, 2011. 


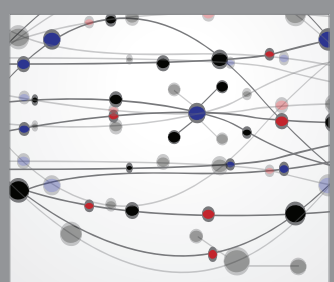

The Scientific World Journal
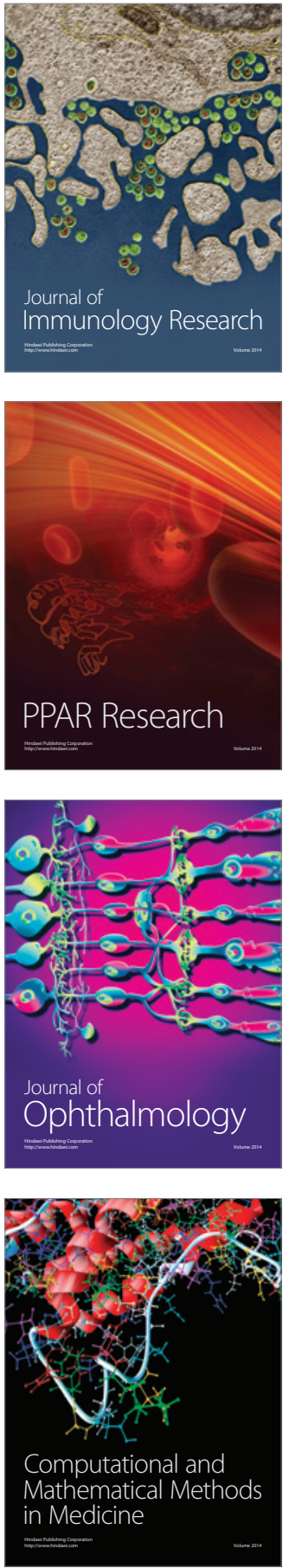

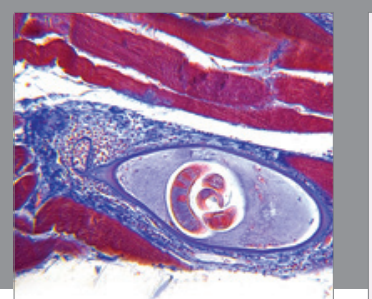

Gastroenterology Research and Practice

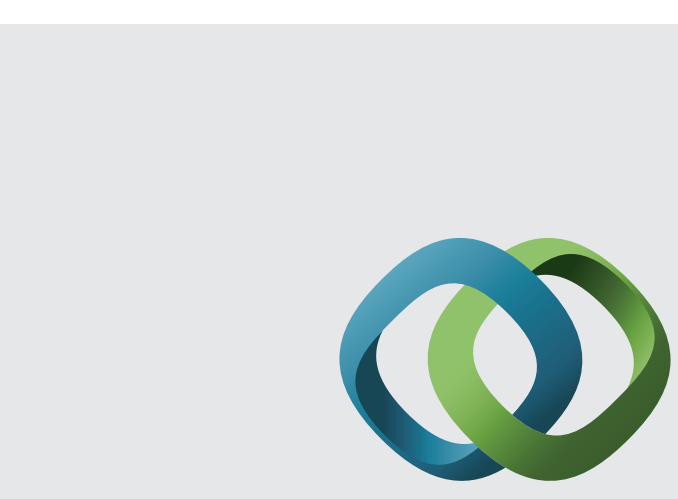

\section{Hindawi}

Submit your manuscripts at

http://www.hindawi.com
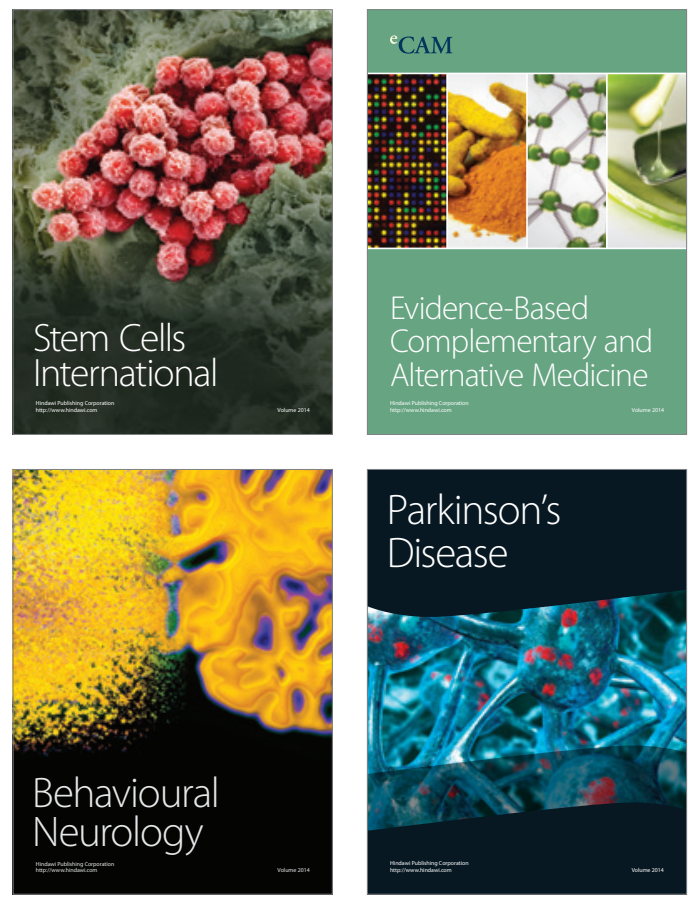
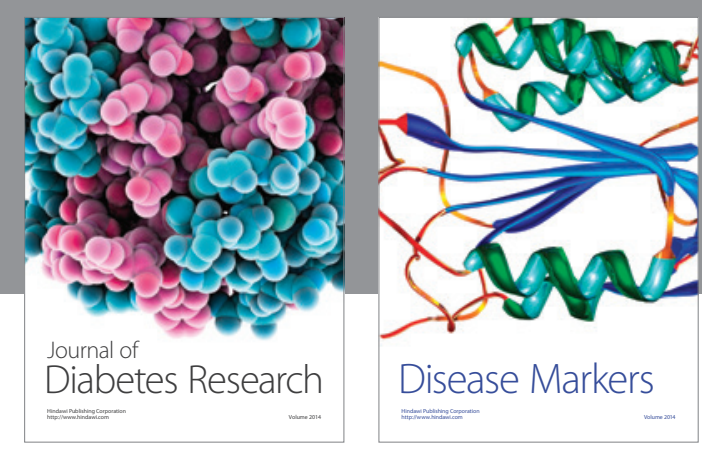

Disease Markers
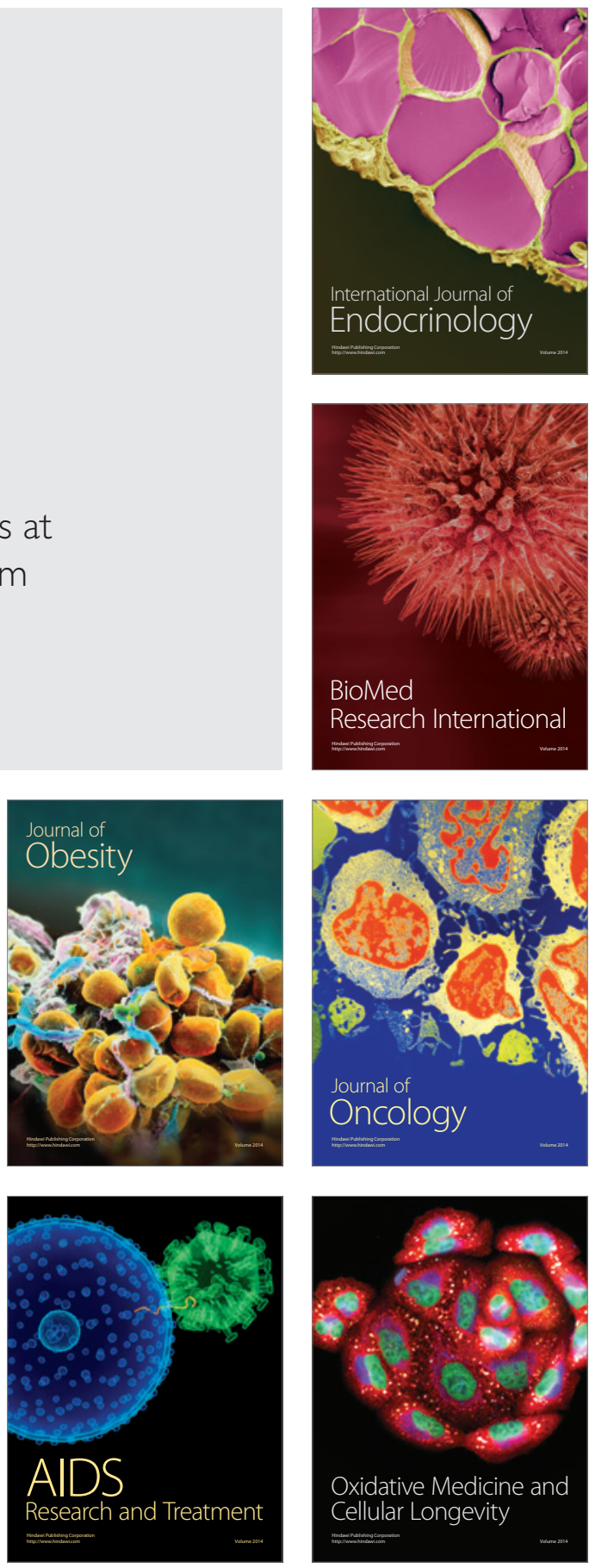